2. World Health Organization. Chemotherapy of leprosy. World Health Organ Tech Rep Ser. 1994;847:1-24.

3. Duncan ME, Pearson JM, Ridley DS, Melsom R, Bjune G. Pregnancy and leprosy: the consequences of alterations of cell-mediated and humoral immunity during pregnancy and lactation. Int J Lepr Other Mycobact Dis. 1982;50:425-35.

4. World Health Organization. WHO model prescribing information: drugs used in leprosy [cited 2019 Jan 20]. https://apps.who.int/ medicinedocs/en/d/Jh2988e

5. Gimovsky AC, Macri CJ. Leprosy in pregnant woman, United States. Emerg Infect Dis. 2013;19:1693-4. http://dx.doi. org/10.3201/eid1910.130463

6. Shale MJ. Women with leprosy. A woman with leprosy is in double jeopardy. Lepr Rev. 2000;71:5-17. http://dx.doi.org/10.5935/ 0305-7518.20000003

7. Ozturk Z, Tatliparmak A. Leprosy treatment during pregnancy and breastfeeding: a case report and brief review of literature. Dermatol Ther (Heidelb). 2017;30:e12414. http://dx.doi.org/ 10.1111/dth.12414

8. Listed N. The final push strategy to eliminate leprosy as a public health problem: questions and answers. Lepr Rev. 2002;73:279-81.

Address for correspondence: Hongsheng Wang, Institute of Dermatology, Chinese Academy of Medical Sciences, Department of Mycobacterium, St. 12 Jiangwangmiao, Nanjing, Jiangsu 210042, China; email: whs33@, vip.sina.com; Junhua Li, Hunan Provincial Center for Disease Control and Prevention, Changsha, Hunan, China; email: hncdcbgs@126.com

\title{
Zoonotic Virus Seroprevalence among Bank Voles, Poland, 2002-2010
}

\section{Maciej Grzybek, Tarja Sironen, Sanna Mäki, Katarzyna Tołkacz, Mohammed Alsarraf, Aneta Strachecka, Jerzy Paleolog, Beata Biernat, Klaudiusz Szczepaniak, Jolanta Behnke-Borowczyk, Antti Vaheri, Heikki Henttonen, Jerzy M. Behnke, ${ }^{1}$ Anna Bajer ${ }^{1}$}

Author affiliations: Medical University of Gdansk, Gdansk, Poland (M. Grzybek, B. Biernat); University of Helsinki, Helsinki, Finland (T. Sironen, S. Mäki, A. Vaheri); University of Warsaw, Warsaw, Poland (K. Tołkacz, M. Alsarraf, A. Bajer); University of Life Sciences in Lublin, Lublin, Poland (A. Strachecka, J. Paleolog, K. Szczepaniak); Poznan University of Life Sciences, Poznan, Poland (J. Behnke-Borowczyk); Natural Resources Institute Finland, Helsinki (H. Henttonen); University of Nottingham, Nottingham, UK (J.M. Behnke)

DOI: https://doi.org/10.3201/eid2508.190217

${ }^{1}$ These authors contributed equally to this article.
Bank voles in Poland are reservoirs of zoonotic viruses. To determine seroprevalence of hantavirus, arenavirus, and cowpox virus and factors affecting seroprevalence, we screened for antibodies against these viruses over 9 years. Cowpox virus was most prevalent and affected by extrinsic and intrinsic factors. Long-term and multisite surveillance is crucial.

$\mathrm{T}$ he most prevalent rodentborne zoonotic viruses in Europe are hantaviruses, lymphocytic choriomeningitis virus (LCMV), cowpox virus (CPXV), and Puumala virus (PUUV) (1). In 2016, a total of 18 countries in Europe reported 2,190 cases of hantavirus disease, mainly caused by PUUV. The occurrence of rodentborne viruses in Poland is not well documented. The first outbreak of hantavirus infections among humans ( 9 cases) was reported in 2007. During 2012-2016, a total of 79 cases of hantavirus infections were reported in Poland, 55 of them in Podkarpackie Province in 2014 (2). In 2015, a case of human cowpox infection was reported in Poland (3).

We conducted a multisite, long-term study of hantavirus and arenavirus seroprevalence in northeastern Poland. Our objectives were to monitor seroprevalence of LCMV, CPVX, and PUUV in 3 populations of bank voles (Myodes glareolus) from ecologically similar but disparate sites in northeastern Poland and to analyze intrinsic (host sex, host age) and extrinsic (study year, study sites) factors that might affect seroprevalence among these rodent populations.

Study sites were located in the Mazury Lake District region in northeastern Poland (Appendix Figure 1, https:// wwwnc.cdc.gov/EID/article/25/8/19-0217-App1.pdf). The sites and methods used for trapping rodents and sampling and processing trapped animals have been described (4). We analyzed serum samples by using an immunofluorescence assay (IFA) (Appendix Figure 2). We diluted serum samples 1:10 in phosphate-buffered saline and tested their reactivity to hantaviruses by using a PUUV IFA, to cowpox viruses by using a CPXV IFA, and to arenaviruses by using an LCMV IFA (5). IFAs were conducted as previously described $(6,7)$. The statistical approach has been comprehensively documented (4).

We tested 652 bank voles and detected antibodies against all 3 viruses. Overall seroprevalence of combined viral infections was $25.9 \%$ (95\% CI $23.0 \%-29.1 \%$ ), but most infections were attributable to CPXV (seroprevalence $25 \%$ [ $95 \%$ CI $22.1 \%-28.2 \%]$ ]). Only 2 voles were LCMV seropositive $(0.3 \%$ [ $95 \%$ CI $0.2 \%-0.9 \%])$, and only 5 were PUUV seropositive $(0.76 \%$ [ $95 \%$ CI $0.4 \%-1.6 \%]$ ). We therefore confined further analyses to CPXV.

The effect of study year on CPXV seroprevalence (by $\chi^{2} /$ d.f. $)$ was highly significant $\left(\chi_{2}^{2} 31.2 ; p<0.001\right)$; seroprevalence was 2.7 times higher among bank voles sampled in 

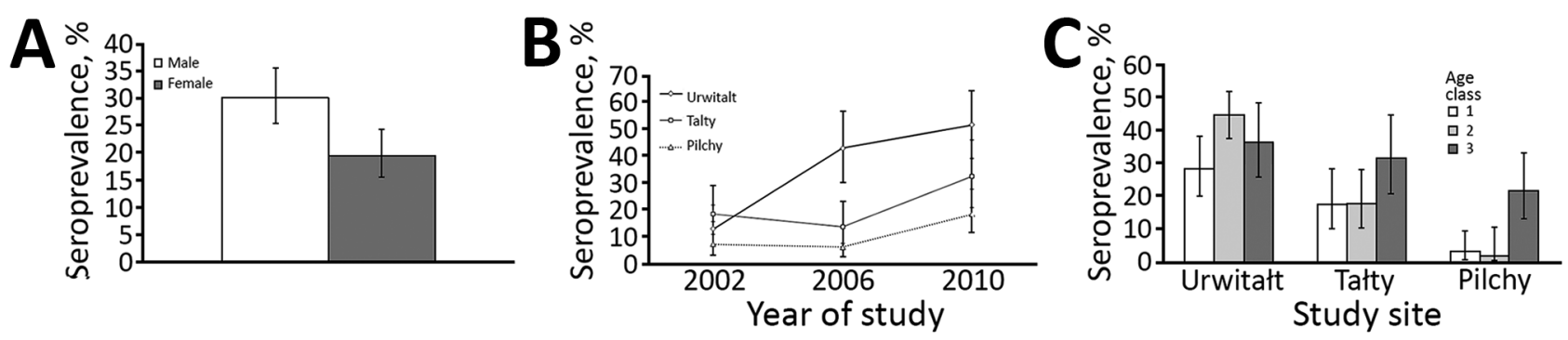

Figure. Seroprevalence of cowpoxvirus (CPXV) in bank voles in Poland, 2002-2010. A) By sex; B) by study site location and year of study; C) by study site location and vole age class (class 1-immature juvenile bank voles; class 2-mostly young adult bank voles; and class 3-breeding older animals). Error bars indicate $95 \% \mathrm{Cl}$.

$2010(36.1 \%[95 \%$ CI $31.7 \%-40.7 \%])$ than in $2002(13.1 \%$ [7.4\%-21.0\%]). CPXV seroprevalence also varied markedly among voles from the 3 study sites $\left(\chi_{2}^{2} 46.84 ; \mathrm{p}<0.001\right)$; seroprevalence was highest among voles from Urwitalt (38.4\% [95\% CI 33.9\%-43.1\%]) and lower among voles from Tałty $(23.0 \%[19.3 \%-27.2 \%])$ and Pilchy $(10.3 \%$ [95\% CI 5.7\%-17.4\%]). CPXV seroprevalence was also significantly affected by the sex of the host $\left(\chi^{2}, 10.1 ; \mathrm{p}=\right.$ $0.001)$ and was 1.5 times higher for male than female voles (Figure, panel A). Seroprevalence increased with host age $\left(\chi_{2}^{2} 12.73 ; p=0.002\right)$ and was lowest among voles from age class 1 (immature) $(16.0 \%$ [95\% CI 10.0\%-24.1\%]) and higher among those from age class 2 (mostly young adults) (27.2\% [95\% CI 23.2\%-31.5\%]) and age class 3 (breeding older adults) (30.1\% [95\% CI 25.9\%-34.6\%]).

The differences in seroprevalence between sites were also confounded by interaction with study year (year $\times$ site $\times$ presence/absence of antibodies against CPXV; $\chi_{4}^{2} 12.76$; $\mathrm{p}=0.012$ ). Seroprevalence increased significantly at all 3 study sites from 2006 to 2010 and was highest in Urwitałt (0.83-fold). The largest seroprevalence increases from 2006 to 2010 were in Tałty (2.35-fold) and Pilchy (2.9fold) (Figure, panel B).

The pattern of age-related changes in seroprevalence also differed between study sites (site $\times$ age $\times$ presence/absence of antibodies against $\left.\mathrm{CPXV} ; \chi_{4}^{2}=17.45 ; \mathrm{p}=0.002\right)$ (Figure, panel C). In Urwitałt, the overall seroprevalence was highest among voles in age class 2 (44.5\% [95\% CI $37.5 \%-51.8 \%]), 1.57$-fold lower among voles in age class 1 , and 1.22-fold lower among voles in age class 3. In Tałty and Pilchy, seroprevalence was highest among voles from age class 3. In Tałty, seroprevalence was 1.8-fold higher among voles in age class 3 compared with voles in other age classes. In Pilchy, seroprevalence among voles in age class 3 was 10.8 -fold higher than among voles in age class 2 .

Our data show that CPXV was the dominant viral pathogen among bank voles in Poland during the study period, although PUUV and LCMV were also found. Our finding that the highest seroprevalence was among bank voles from Urwitałt complements our previous reports on other pathogens, reflects the importance of extrinsic effects on prevalence, and establishes that the sites from which host populations are sampled is the most influential factor affecting prevalence (4).

Our results provide additional information about the role of bank voles in Poland as infectious virus reservoirs. Although short-term cross-sectional studies are useful as a starting point (8), to obtain a comprehensive ecologic picture, long-term monitoring (several years and preferably a decade or longer) and a multisite approach are crucial. Identifying rodent species that can serve as reservoirs for zoonotic disease viruses and predicting regions where new outbreaks are most likely to happen are crucial steps for preventing and minimizing the extent of zoonotic disease among humans (9).

\section{Acknowledgments}

We thank the University of Nottingham, Warsaw University, and the Medical University of Gdansk for financial support. M.G. thanks Alicja Rost and Ewa Zieliniewicz for their assistance in the laboratory.

This research received support from Sigrid Jusélius Foundation, Helsinki, and the Natural Resources Institute Finland. J.M.B. received support from the Royal Society, the British Ecological Society, and the Grabowski Fund. A.B. received support from the Polish State Committee for Scientific Research and the British Council's Young Scientist Programme. M.G. received support from the Ministry of Science and Higher Education in Poland, Fellowship for Outstanding Scientists (428/STYP/11/2016).

\section{About the Author}

Dr. Grzybek is a parasitologist holding the position of assistant professor in the Department of Tropical Parasitology, Medical University of Gdansk, Poland. His research interests include epidemiology and ecology of macroparasites and microparasites in rodents, especially bank voles. He is also interested in hostparasite interactions and intrinsic and extrinsic factors that influence these relationships. 


\section{References}

1. Kallio-Kokko H, Uzcategui N, Vapalahti O, Vaheri A. Viral zoonoses in Europe. FEMS Microbiol Rev. 2005;29:1051-77. http://dx.doi.org/10.1016/j.femsre.2005.04.012

2. European Centre for Disease Prevention and Control. Hantavirus infection. Annual epidemiological report for 2016 [cited 2019 June 20]. https://ecdc.europa.eu/sites/portal/files/documents/ hantavirus-infection-annual-epidemiological-report-2016.pdf

3. Świtaj K, Kajfasz P, Kurth A, Nitsche A. Cowpox after a cat scratch-case report from Poland. Ann Agric Environ Med. 2015;22:456-8. http://dx.doi.org/10.5604/12321966.1167713

4. Grzybek M, Bajer A, Bednarska M, Al-Sarraf M, Behnke-Borowczyk J, Harris PD, et al. Long-term spatiotemporal stability and dynamic changes in helminth infracommunities of bank voles (Myodes glareolus) in NE Poland. Parasitology. 2015;142:1722-43. http://dx.doi.org/10.1017/S0031182015001225

5. Hedman K, Vaheri A, Brummer-Korvenkontio M. Rapid diagnosis of hantavirus disease with an IgG-avidity assay. Lancet. 1991;338:13536. http://dx.doi.org/10.1016/0140-6736(91)92235-T

6. Kallio-Kokko H, Laakkonen J, Rizzoli A, Tagliapietra V, Cattadori I, Perkins SE, et al. Hantavirus and arenavirus antibody prevalence in rodents and humans in Trentino, Northern Italy. Epidemiol Infect. 2006;134:830-6. http://dx.doi.org/10.1017/S0950268805005431

7. Pelkonen PM, Tarvainen K, Hynninen A, Kallio ERK, Henttonen K, Palva A, et al. Cowpox with severe generalized eruption, Finland. Emerg Infect Dis. 2003;9:1458-61. http://dx.doi.org/10.3201/ eid0911.020814

8. Sadkowska-Todys M, Dudek-Godeau D, Kamińska S, BaumannPopczyk A, Czerwiński M, Kucharczyk B, et al. Occurrence and maintenance of hantavirus infections among rodent populations in their natural habitat — results of a field study from Podkarpackie Province, Poland 2010-2012. Przegl Epidemiol.2015; 69:283-8, 395-9.

9. Han BA, Schmidt JP, Bowden SE, Drake JM. Rodent reservoirs of future zoonotic diseases. Proc Natl Acad Sci U S A. 2015; 112:7039-44. http://dx.doi.org/10.1073/pnas.1501598112

Address for correspondence: Maciej Grzybek, Medical University of Gdansk, Department of Tropical Parasitology, Powstania Styczniowego 9B, 81-519 Gdynia, Poland; email: maciej.grzybek@gumed.edu.pl

\section{Polio-Like Manifestation of Powassan Virus Infection with Anterior Horn Cell Involvement, Canada}

\section{Christopher Picheca, ${ }^{1}$ Vignan Yogendrakumar, ${ }^{1}$ James I. Brooks, Carlos Torres, Elizabeth Pringle, Jocelyn Zwicker}

Author affiliation: University of Ottawa, Ottawa, Ontario, Canada

DOI: https://doi.org/10.3201/eid2508.190399

${ }^{1}$ These first authors contributed equally to this article.
Evidence of spinal cord involvement in Powassan virus infection is largely limited to mouse models. We report a case of a polio-like illness caused by Powassan virus infection in a 62-year-old man in Canada. Magnetic resonance imaging showed T2 hyperintensities in the anterior horns of the cervical spinal cord.

$\mathrm{P}$ owassan virus (POWV) is a tickborne flavivirus, named after Powassan, Ontario, Canada, the location of the first documented human infection in 1958 (1). Since then, $\approx 150$ cases of POWV infection have been reported globally, and incidence has increased over time. A total of 125 POWV cases have been identified since 2008, 33 (26\%) in 2017 (2). In Canada, most reported POWV infections have been in the Great Lakes region. A small number of cases have been reported in the Maritime provinces (3).

POWV is transmitted by members of the Ixodes genus of ticks, including I. cookei and the more opportunistic and aggressive I. scapularis. POWV has 2 lineages; lineage 2 (deer tick virus) has emerged quickly in parts of North America, along with the expanding range of I. scapularis ticks.

POWV infection typically begins with prodromal symptoms including fever, nausea, headache, and myalgia. Central nervous system involvement includes an altered level of consciousness, paralysis, or ophthalmoplegia (4). POWV encephalitis has a $10 \%$ mortality rate, and $\leq 50 \%$ of survivors suffer residual deficits (5). Studies with mice have demonstrated that POWV can affect motor neurons in the anterior horns of the spinal cord (6). These same neurons are affected by poliovirus, West Nile virus, and enterovirus D68 (7). However, POWV infection with cord involvement in humans is not well documented; 1 human case demonstrated motor neuron pathology after POWV lineage 2 infection (8), and a second case with suspected motor neuronopathy was reported in 2018 (9).

We present the case of a 62-year-old man living in urban Ontario who experienced nausea, vomiting, and abdominal pain while vacationing in rural Newfoundland. He sought treatment at a hospital in Nova Scotia and experienced diplopia and ataxia. A computed tomography scan of the head did not show any acute intracranial event.

The patient became febrile and experienced dysarthria, weakness, and respiratory distress. Cerebrospinal fluid analysis showed pleocytosis $\left(159 \times 10^{6}\right.$ total nucleated cells: $42 \%$ neutrophils, $43 \%$ lymphocytes) and elevated protein levels $(0.79 \mathrm{~g} / \mathrm{L})$. He was started on empiric treatment with ceftriaxone, ampicillin, acyclovir, and dexamethasone. Results of tests for Cryptococcus, HIV, syphilis, Lyme disease, herpes simplex viruses 1 and 2 , varicella zoster virus, and acid-fast bacilli were negative. Initial arbovirus serology results were negative. The patient worsened, requiring intubation and transfer to an intensive care unit. 